\section{Just \\ around \\ the corner}

For 50 years, physicists have been

promising that power from nuclear

fusion is imminent. Now they are

poised to build an experiment that

could vindicate their views.

But will the machine work?

Geoff Brumfiel investigates.

\section{IMAGE \\ UNAVAILABLE \\ FOR COPYRIGHT \\ REASONS}

$\mathbf{W}$ hen word came last month that a site had finally been chosen for the international fusion experiment ITER, Gerald Navratil summed up his feelings in a single word: "relief". Navratil, a plasma physicist at Columbia University in New York and a member of the US ITER team, had spent the past 18 months on the sidelines, watching helplessly as France and Japan fought over which of them would host the machine.

As the battle raged on, he had seen US support for the project slowly slip away. But with the location for the reactor now fixed in Cadarache, southern France, Navratil is feeling more positive. "Now that we have a site, we can finally proceed in taking the next step," he says.

Fusion research is difficult enough without the politics. The much-vaunted concept of mimicking the Sun and generating power from nuclear fusion has been an unfulfilled promise for some 50 years. Even to get this far, researchers have had to overcome formidable technical and scientific barriers. But they hope that ITER will at last prove to doubting politicians and scientific colleagues that nuclear fusion is a viable energy source. If all goes well, funding from ITER's six international partners - China, the European Union, Japan, South Korea, Russia and the United States - could be in place this winter, allowing construction to begin in 2006, and operation in 2016.

ITER is designed to heat hydrogen to hundreds of millions of degrees centigrade, and then squeeze energy from the resulting plasma, while holding it stable for minutes at a time. Although most fusion researchers agree that the reactor will probably be able to generate more power than it consumes, there are some who believe it may struggle to produce as much energy as predicted, or to hold the plasma stable for as long as hoped. "Like any good scientific experiment, there's a chance that it won't work," says William Dorland, a theoretical plasma researcher at the University of Maryland in College Park.

But ITER is not just any scientific experiment. With construction costs of US $\$ 5.5$ billion, it will be one of the most expensive scientific facilities ever built on Earth. "ITER will do what it's supposed to do and give renewed credibility to the field," asserts Richard Hazeltine, a plasma physicist at the University of Texas at Austin and head of the Fusion Energy Sciences Advisory Committee for the US Department of Energy.

\section{Collision course}

Fusion is a simple idea that is hard to achieve in practice. Unlike fission, which generates power from the decay of heavy atomic nuclei, fusion occurs when lightweight nudei, usually from hydrogen, collide with each other and fuse together to form a new element, typically helium. Those collisions are difficult to orchestrate because the positively charged

\section{"Fusion science is on the edge of} vanishing - we need to go ahead and turn this damn thing on." - Richard Hazeltine nuclei must overcome their natural repulsion. This only occurs when they are moving very fast or are packed closely together. In other words, you need a very hot, dense plasma to achieve fusion power.

The nearest natural source of fusion energy is the Sun. Within its core, gravity pulls positively charged hydrogen nuclei together until * they become hot enough and dense enough to fuse into helium. But here on Earth, more inventive solutions are needed.

Shortly after the Second World War, scientists in the United States and Russia began to work on machines that might be able to heat and pressurize hydrogen by squeezing the atoms within strong magnetic fields. Scientists experimented with many different machines, each with their own advantages and quirks, but by the 1960s their search had narrowed towards a single design: the tokamak.

Developed by Russian physicists Andrei Sakharov and Igor Tamm, the tokamak is a doughnut-shaped machine that uses a series of overlapping magnetic fields to hold a hot, dense plasma within the reactor walls (see graphic). Throughout the 1970s, tokamak technology advanced rapidly, leading many to believe it could be fashioned into a prototype power plant by the start of this century.

Those predictions proved to be too optimistic. The energetic hydrogen gas that tokamaks were meant to contain defied confinement by leaking out of its magnetic shackles. Researchers found themselves battling poorly understood plasma instabilities and turbulence, and made slow progress. Even today only one machine, the JT-60 tokamak in 


\section{ITER'S TOKAMAK - TOO HOT TO HANDLE}

Fusion scientists often describe the job of containing a hot plasma

in magnetic fields as akin to holding jelly using rubber bands.

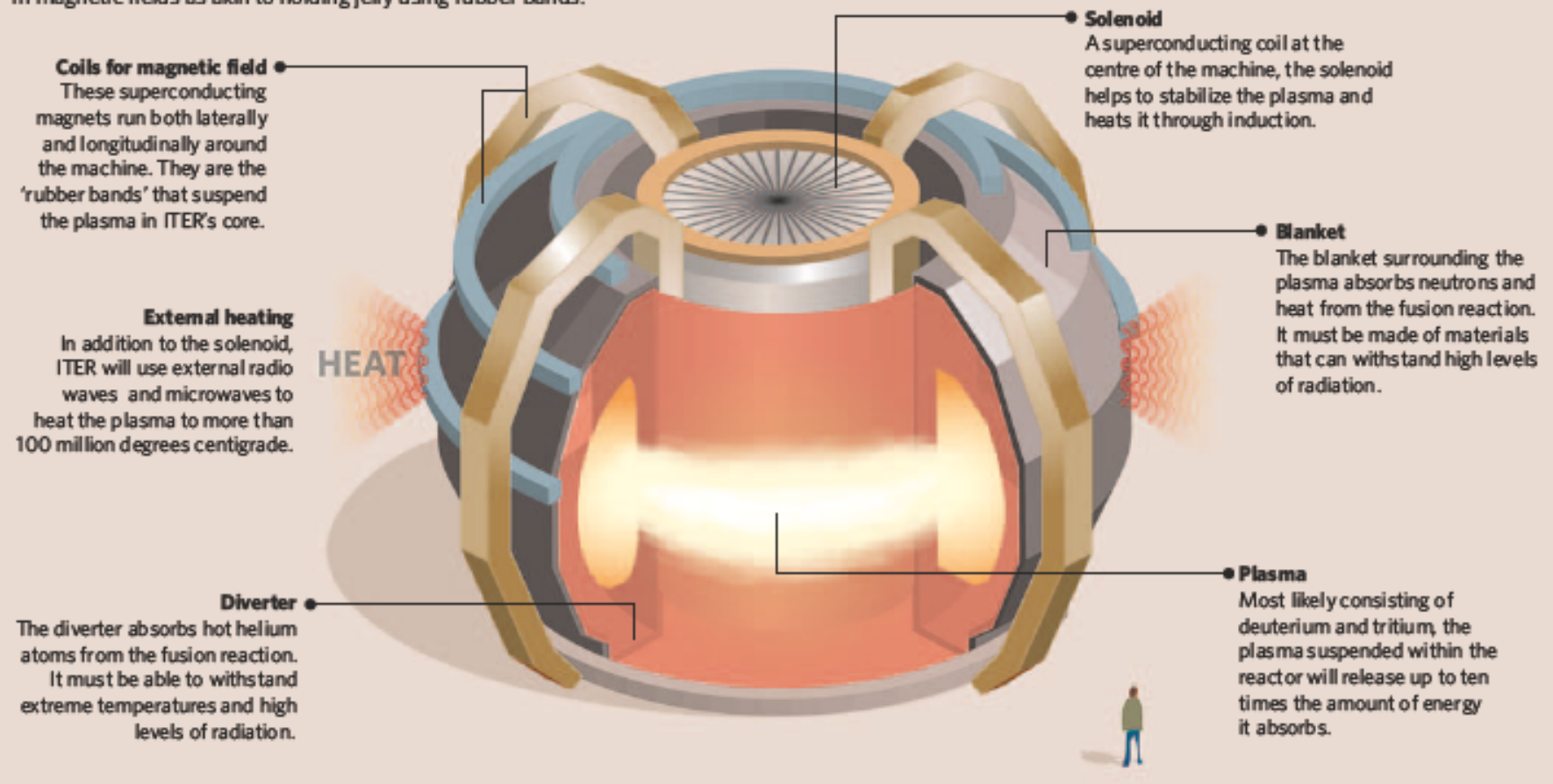

Naka, Japan, has begun to approach the 'break-even point' at which as much energy comes out of the device as goes into it.

Nevertheless, when ITER was first proposed in 1985 , the tokamak design was the obvious choice, says Roberto Andreani, who directs the technical efforts of the European Fusion Development Agreement in Garching, Germany. "In all the years that we have studied fusion, I would say that the tokamak has been the most reliable," he says. "It is the only reasonable choice for ITER"

\section{Fuel for thought}

ITER's ambitious goal is to hold its hydrogen fuel (a mixture of deuterium and tritium, two isotopes of hydrogen) tightly for between seven and fifteen minutes, while heating it to more than 100 million degrees centigrade and squeezing out about 500 megawatts of energy. The current world record for a sustained hightemperature, high-pressure plasma, held by the JT- 60 , is 24 seconds. To reach its goals, ITER will use superconducting magnets $25 \%$ stronger than those in the Japanese machine, and a host of external heating techniques.

ITER's other main advantage will be its size, says Raymond Fonck of the University of Wisconsin at Madison, a member of the ITER design team. Put simply, the more space a hot plasma has to roam, the better it will behave, Fonck explains. With an outer radius of 6.2 metres and a plasma volume of $840 \mathrm{~m}^{3}$, ITER will be twice as big as any previous tokamak.

But even with its high magnetic fields and enormous size, the machine faces some serious challenges, says Dorland. Unlike previous machines, ITER is designed to release more energy than it takes in, he says. In the past, researchers have been able to control the plasma temperature simply by turning down the heat. But if ITER succeeds, the plasma will burn under the power of its own fusion reactions, and that means researchers will have to learn how to manage the power output. "The name of the game is to hold a lot of energy into a small place and let it out in a controlled fashion, and that's not easy, he says.

Most of the energy released by ITER will be

\section{,}

Atsome point a commercialfusion reacto

will need to find a way to use the excess heat that is generated. Although ITER is not designed to do this, future machines will be expected to produce useful energy. Most likely, liquid coolants will be used to cool the blanket and diverter, and the hot coolant leaving the reactor will be used to heat water, which in turn will drive steam turbines.

A big uncertainty with ITER's design is the proliferation of helium inside the reactor. Previous tokamak experiments have produced small amounts of fusion, and so small amounts of helium and neutrons. But this time, ITER will fill with substantially more hot helium, and how that will interact with the rest of the plasma could be unpredictable, says Stewart Prager of the University of Wisconsin and another US physicist on the ITER design team. 


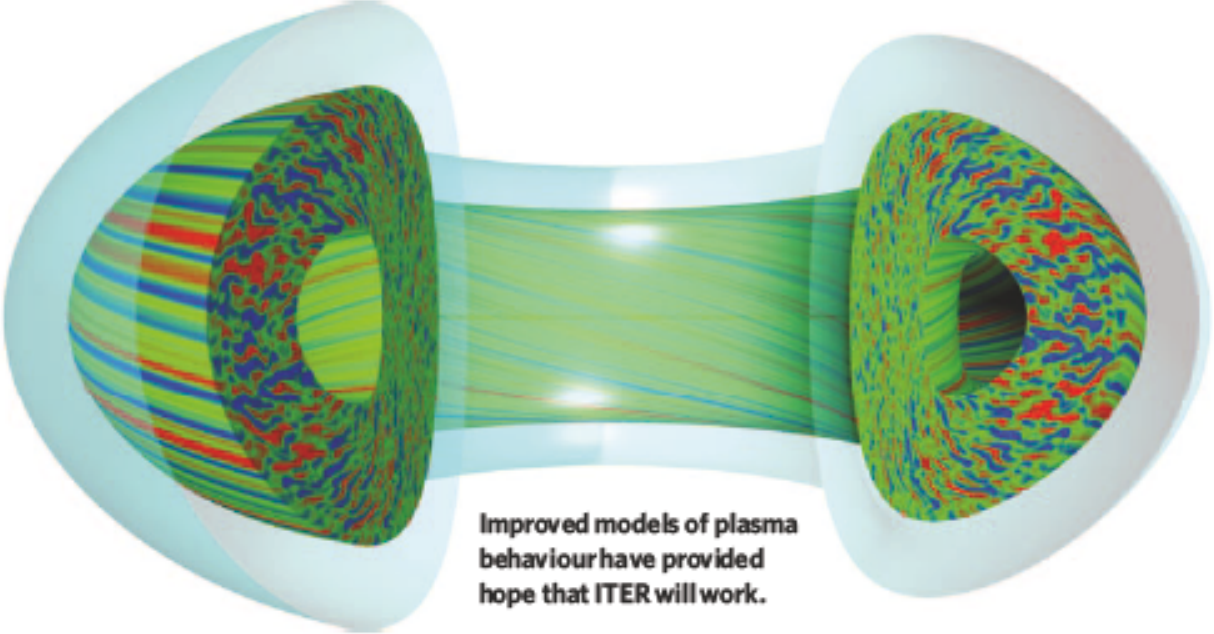

The researchers also worry about the walls accumulating too much radioactive tritium, on which there are strict limits for safety reasons.

It is questions like these that caused ITER to scale back its original plan. The machine was initially slated to be twice as big again, capable of holding burning hydrogen for several hours at a time and releasing some 1,500 megawatts of power. But governments were uneasy about the projected costs, and that, together with technical uncertainties raised by Dorland and others, caused a redesign with more modest goals and a smaller price tag.

Some of the technical concerns resulted from numerical simulations of plasma turbu- from where we are to ITER. ${ }^{\text {x }}$ Ward says that the reactor will provide definitive proof of the value of fusion power, as well as offering technical information about how to build a firstgeneration commercial reactor.

Dorland agrees, with one caveat: "I think that ITER will work, but I'm willing to bet you $\$ 100$ that another fusion device will get more power out before it does," he says. There are perhaps half-a-dozen designs that might catch up with tokamaks, but the most impressive to date, he says, is a variation of the tokamak called the spherical torus. This more closely resembles a pitted apple than a doughnut, a shape that allows it to create a sharp boundary between the hot hydrogen plasma and the outer wall of the reactor and squeeze the plasma more tightly. Such a design might achieve a burning fusion reaction with less fuss than the more cumbersome tokamak, he says.

Even so, those who have been in the fusion business a long time believe that it is better to go ahead with ITER than to hope another device will get there first, says Hazeltine. Decades of promises and billions in investment have left international fusion research in what he describes as a fragile condition. "Fusion science is on the edge of vanishing", he says. "I think we need to go ahead and turn this damn thing on."

Geoff Brumfiel is Nature's Washington physical sciences correspondent.

\section{Material gains in the east}

With Europe ploughing all of its fusion funds into the ITER experiment in France, the Japanese fusion community is poised to take the lead in several supporting projects. Japan could build facilities related to materials testing, upgrade its JT- 60 tokamak (pictured) for new plasma experiments, and host a design centrefor DEMO, the demonstration power plant that will follow in ITER's wake.

Notable among these candidate projects is the International Fusion Materials Irradiation Facility (IFMIF). This would aim to verify whether key structural materials, including the blanket (seegraphic), can withstand the onslaught of high-energy neutrons that a fusion reactor's plasma will throw at them. IFMIF will require a linear particle accelerator to generate neutrons with energies of about 14 mega-electronvolts and at intensities orders of magnitude higher than existing sources.

The ability of materials to withstand the high-energy neutrons created by ITER and DEMO has neverbeen tested at such high intensities, and the IFMIF experiments are essential to prove to safety regulators that these machines will survive such extreme conditions, says Yoshikazu Okumura, a fusion scientist at the Japan Atomic Energy Research Institute (JAERI) in Naka. "At the moment, we just don't have any data," he says.

High-energy neutrons can displace atoms from theirpositions in the structural materials and eventually weaken them. ITER is designed to experience short-term pulses of the fusion reactions, so structural damage should be minor. In DEMO, which would need to operatecontinuously for years, the accumulated toll of these destabilizing neutrons is likely to be more than 30 times what it will be for ITER.

The currentchoice for ITER's main structure is stainless steel, whereas DEMO may use a heatresistant 'ferritic steel', which will endure radiation more readily. But as fusion scientists aim for higher efficiency - and so higher temperatures - new materials, such as silicon carbide, might be

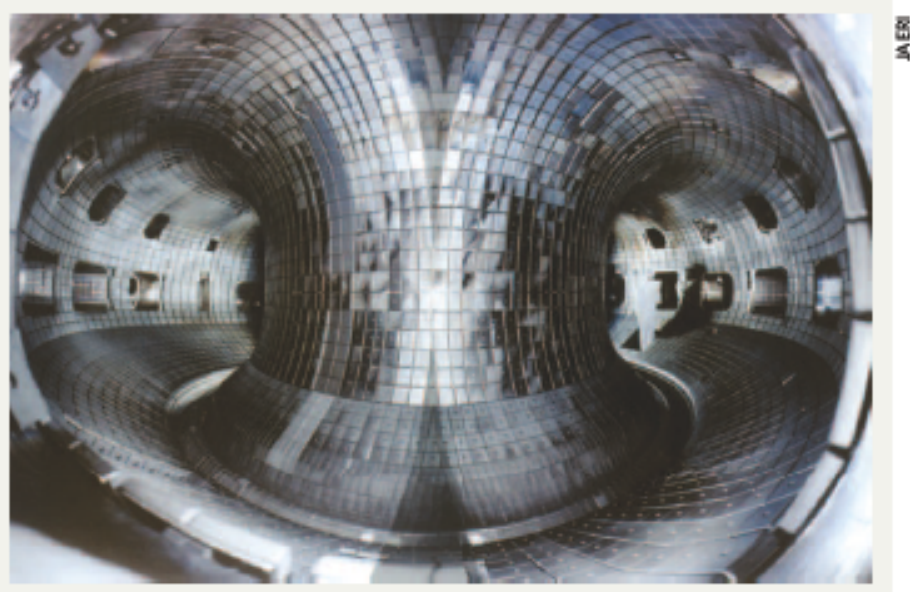

needed. "Every country has its own view on how to balance efficiency with safety," says Hideyuki Takatsu, deputy director of JAERI's fusiontechnology division.

But at $¥ 310$ billion (US $\$ 2.6$ billion) for the 40 -year project roughly one quarter of ITER's price tag - it is not certain whether IFMIF will ever be built, nor whether it would be in Jap an, says Takatsu. Other ITER partners, such as Britain, are keen to host IFMIF, and with some expressing frustration at the financial deal secured by the Japanese for its future role in ITER (see Nature 435, $1142-1143 ; 2005)$, the negotiations over IFMIF could become fractious.

But the facility is needed to give a boost to materials science, a field thatmany fusion researchers say has been neglected. "Materials research has had only about $1-2 \%$ of the fusion budget," says Hideki Matsui, a materials scientist at Tohoku University. “There's been an imbalance."

David Cyranoski 